\title{
Pengaruh usia perusahaan terhadap kinerja keuangan (Studi pada Bank Victoria Syariah)
}

\author{
1*Jeffry Andhika Putra \\ ${ }^{1}$ Universitas Janabadra, Yogyakarta \\ *e-mail korespondensi: jeffry@janabadra.ac.id
}

\begin{tabular}{l|l}
\hline \hline \multicolumn{1}{c}{ Article Info } & \multicolumn{1}{c}{ Abstract } \\
\hline \hline $\begin{array}{l}\text { Keywords: } \\
\text { company age, } \\
\text { financial } \\
\text { performance, return } \\
\text { on assets, return on } \\
\text { equity, sharia bank }\end{array}$ & $\begin{array}{l}\text { Company age and experience are concepts that remain the same. Younger and older } \\
\text { companies differ in experience and other aspects. The company's innovation } \\
\text { activities change over time and the age of the company reflects the process of growth } \\
\text { corporate innovation because of its learning effect, which enables mature companies } \\
\text { to innovate more effectively as they build on previous routines and capabilities. Over } \\
\text { time, companies can not only innovate based on past experience and capabilities, } \\
\text { but can also accumulate resources, managerial knowledge, and the ability to handle } \\
\text { uncertainty. The purpose of this study was to determine the effect of company age on } \\
\text { financial performance, as measured by return on assets (ROA) and return on equity } \\
\text { (ROE). The results of the regression analysis show that the age of the company has } \\
\text { no effect on ROA and ROE. Based on the results of this study, the management of } \\
\text { Bank Victoria Syariah should try to increase market share to increase financial } \\
\text { performance, for example by intensifying promotions and corporate cooperation. }\end{array}$ \\
\hline \hline
\end{tabular}

Info Artikel

Kata Kunci: usia perusahaan, kinerja keuangan, return on assets, return on equity, bank syariah
Usia dan pengalaman perusahaan adalah konsep yang tetap sama. Perusahaan yang lebih muda dan lebih tua berbeda dalam pengalaman dan aspek lainnya. Aktivitas inovasi perusahaan berubah dari waktu ke waktu dan usia perusahaan mencerminkan proses pertumbuhan dan akumulasi pengalaman. Usia dianggap sebagai penentu penting inovasi perusahaan karena adanya efek pembelajaran, yang memungkinkan perusahaan dewasa untuk berinovasi lebih efektif karena mereka membangun rutinitas dan kemampuan sebelumnya. Seiring waktu, perusahaan tidak hanya dapat berinovasi berdasarkan pengalaman dan kemampuan masa lalu, tetapi juga dapat mengakumulasi sumber daya, pengetahuan manajerial, dan kemampuan menangani ketidakpastian. Tujuan penelitian ini adalah untuk mengetahui pengaruh usia perusahaan terhadap kinerja keuangan, yang diukur dengan return on assets (ROA) dan return on equity (ROE). Hasil analisis regresi menunjukkan bahwa usia perusahaan tidak berpengaruh terhadap ROA dan ROE. Berdasarkan hasil penelitian ini, maka manajemen Bank Victoria Syariah harus berusaha meningkatkan pangsa pasar untuk menambah kinerja keuangan misalnya dengan menggencarkan promosi dan kerjasama korporat. 


\section{PENDAHULUAN}

Para peneliti telah menggarisbawahi peran kunci yang dimainkan oleh the age of knowledge inputs (Vimalnath et al., 2018). Usia dan pengalaman perusahaan bukanlah konsep yang persis sama (Baum \& Ingram, 1998; Desai, 2008). Perusahaan yang lebih muda dan lebih tua berbeda dalam pengalaman dan aspek lainnya (Ouimet \& Zarutskie, 2014), dan teori yang berbeda memiliki argumen yang berbeda tentang hubungan antara usia perusahaan dan pengalaman (Desai, 2008).

Aktivitas inovasi perusahaan berubah dari waktu ke waktu dan usia perusahaan mencerminkan proses pertumbuhan dan akumulasi pengalaman (Coad et al., 2016; GarcíaQuevedo et al., 2014). Usia dianggap sebagai penentu penting inovasi perusahaan karena adanya efek pembelajaran, yang memungkinkan perusahaan dewasa untuk berinovasi lebih efektif karena mereka membangun rutinitas dan kemampuan sebelumnya (Fan \& Wang, 2019). Seiring waktu, perusahaan tidak hanya dapat berinovasi berdasarkan pengalaman dan kemampuan masa lalu, tetapi juga dapat mengakumulasi sumber daya, pengetahuan manajerial, dan kemampuan menangani ketidakpastian (Fan \& Wang, 2019).

Pertumbuhan research and development (R\&D) perusahaan khususnya di Cina telah memimpin pasar global dalam skala dan cakupannya dengan memanfaatkan keunggulan mereka dalam biaya kompetitif untuk mempromosikan inovasi dan menuai kemampuan teknologi untuk sukses di pasar dunia (Woetzel et al., 2019). BUMN menyumbang sebagian besar ekonomi China dan hubungan politik mereka dengan pemerintah China kemungkinan memfasilitasi pembiayaan investasi (Cheng et al., 2017), memungkinkan mereka untuk berinvestasi lebih banyak dalam R\&D.

\section{KAJIAN TEORI DAN HIPOTESIS}

Penelitian yang dilaksanakan (Younis \& Sundarakani, 2020) menunjukkan bahwa terdapat hubungan positif antara ukuran perusahaan dan kinerja lingkungan, kinerja ekonomi dan kinerja sosial tetapi tidak dengan kinerja operasional. Hasil selanjutnya juga menemukan bahwa environmental management system (EMS) bersertifikat dalam perusahaan Uni Emirat Arab memiliki dampak positif pada keempat dimensi kinerja sementara usia perusahaan tidak memiliki hubungan dengan salah satu dari empat hasil kinerja (Younis \& Sundarakani, 2020).

Haykir \& Çelik (2018) menyelidiki hubungan antara usia dan kinerja perusahaan dengan menganalisis perusahaan milik keluarga di negara berkembang yaitu Turki, dengan mengadopsi estimasi kuadrat terkecil biasa untuk periode antara 2008 dan 2016 menggunakan 38 perusahaan milik keluarga yang terdaftar dan non-keuangan. Haykir \& Çelik (2018) menggunakan profitabilitas sebagai proksi untuk kinerja perusahaan, yang didefinisikan sebagai pendapatan sebelum bunga dan pajak dibagi dengan total aset. Hasilnya menunjukkan bahwa terdapat hubungan antara usia dan profitabilitas perusahaan milik keluarga yang menunjukkan bahwa perusahaan yang lebih muda memiliki keuntungan yang lebih tinggi sampai mereka mencapai usia tertentu, ketika mereka melewati ambang 


\section{Entrepreneurship Bisnis Manajemen Akuntansi (E-BISMA), 2(2), 85-91 \\ Jeffry Andhika Putra}

batas itu, perusahaan yang lebih tua berkinerja lebih baik daripada perusahaan yang lebih muda (Haykir \& Çelik, 2018).

Penelitian tentang kinerja keuangan juga dilaksanakan oleh Olarewaju \& Msomi (2021) dimana intellectual capital mempengaruhi kinerja keuangan pada perusahaan-perusahaan di Afrika Selatan. Penelitian yang dilaksanakan Gugler \& Szücs (2016) juga meneliti return on assets dalam kaitannya dengan merger pada pasar ologopoli. Glambosky et al. (2020) meneliti return on assets dalam kaitannya dengan kesejahteraan pada merger dan akuisisi oleh perusahaan pembayar dividen. Return On Asset (ROA) menunjukan kinerja yang berhasil dihasilkan perusahaan dari sisi profitabilitas (Gestanti \& Setiawan, 2019). Perusahaan yang telah lama berdiri memiliki karakteristik yang berbeda, yakni, perusahaan tersebut akan lebih dikenal dan lebih berkembang, memiliki distributor dan supplier, dengan demikian membantu perusahaan meningkatkan ROA melalui biaya yang lebih murah (Gestanti \& Setiawan, 2019).

Penelitian yang dilaksanakan oleh Kieschnick \& Moussawi (2018) menunjukkan bahwa usia perusahaan berkorelasi positif dengan penggunaan utang, itu berkorelasi negatif dengan berapa banyak utang yang digunakan perusahaan, dan juga ditemukan bahwa efek usia perusahaan pada berapa banyak hutang yang digunakan perusahaan terutama disebabkan oleh interaksi antara usia perusahaan dan fitur tata kelolanya, dimana semakin banyak kekuatan yang dimiliki orang dalam, semakin sedikit hutang yang digunakan perusahaan seiring bertambahnya usia. Penelitian Fan \& Wang (2019) mengungkapkan bahwa investasi research and development $(\mathrm{R} \& \mathrm{D})$ berbeda menurut usia perusahaan. Hubungan antara usia perusahaan dan investasi R\&D secara umum berbentuk lonceng, dan jenis kepemilikan utama memoderasi hubungan usia dengan $R \& D$, karena hubungan tersebut lebih dramatis di antara perusahaan yang dimiliki oleh negara (Fan \& Wang, 2019).

Penelitian yang dilaksanakan oleh Chincarini et al. (2020) mendokumentasikan pola penurunan beta yang kuat selama usia perusahaan, karakteristik perusahaan dan proksi informasi menjelaskan pola ini hanya sebagian. Kedekatan yang dirasakan investor terhadap saham individu memainkan peran penting, dan ketika mengontrol usia perusahaan, ada dukungan untuk capital asset pricing model (CAPM). Petruzzelli et al. (2018) berpendapat bahwa perusahaan yang lebih tua mengungguli yang lebih muda ketika mereka menggunakan pengetahuan yang matang; sebaliknya, perusahaan yang lebih muda lebih mampu mengeksploitasi pengetahuan yang baru lahir dan dewasa, dan tentang ukuran perusahaan, diharapkan bahwa perusahaan yang lebih besar menghadirkan kemampuan yang lebih besar untuk berinovasi dengan menggunakan pengetahuan yang baru lahir dan sangat matang, sementara perusahaan yang lebih kecil mengembangkan solusi inovatif yang lebih berharga ketika mereka membangun pengetahuan dengan tingkat kematangan yang moderat. 


\section{METODE PENELITIAN}

Penelitian ini merupakan penelitian kuantitatif (Bajpai, 2018), yang menggunakan satu variabel bebas yaitu usia perusahaan dan dua variabel terikat yaitu return on asset (ROA) dan return on equity (ROE). Data penelitian ini merupakan laporan keuangan triwulanan Bank Victoria Syariah periode Maret 2012 sampai dengan Desember 2019. Analisis regresi digunakan untuk mengetahui pengaruh variabel bebas terhadap variabel terikat (Hoffman, 2021).

\section{HASIL DAN PEMBAHASAN}

Hasil analisis data variabel usia perusahaan terhadap ROA dapat diketahui pada tabel berikut ini:

Tabel 1.

R Square Usia Perusahaan terhadap ROA

\begin{tabular}{ccccc}
\hline Model & $\mathrm{R}$ & $\mathrm{R}$ Square & $\begin{array}{c}\text { Adjusted R } \\
\text { Square }\end{array}$ & $\begin{array}{c}\text { Std. Error of } \\
\text { the Estimate }\end{array}$ \\
\hline 1 & $.162^{\mathrm{a}}$ & .026 & -.006 & 2.26505 \\
\hline a. Predictors: (Constant), AGE & &
\end{tabular}

Tabel 1 diatas menunjukkan angka $\mathrm{R}$ square sebesar 0,026 yang berarti bahwa variabel usia perusahaan mempengaruhi ROA sebesar 2,6\% dan sisanya sebesar 97,8\% dipengaruhi oleh variabel lain selain usia perusahaan.

Tabel 2.

Pengaruh Usia Perusahaan terhadap ROA

\begin{tabular}{ccccccc}
\hline \multirow{2}{*}{ Model } & \multicolumn{2}{c}{ Unstandardized Coefficients } & $\begin{array}{c}\text { Standardized } \\
\text { Coefficients }\end{array}$ & \multirow{2}{*}{$\mathrm{t}$} & Sig. \\
\cline { 3 - 5 } & \multicolumn{2}{c}{$\mathrm{B}$} & Std. Error & Beta & & \\
\hline 1 & (Constant) & .603 & 1.204 & & .501 & .620 \\
& AGE & -.157 & .175 & -.162 & -.901 & .375 \\
\hline
\end{tabular}

a. Dependent Variable: ROA

Tabel 2 diatas menunjukkan angka sig sebesar 0,375 yang berarti bahwa variabel usia perusahaan tidak berpengaruh signifikan terhadap ROA. Persamaan regresi untuk pengaruh terhadap ROA adalah sebagai berikut:

$$
\mathrm{AGE}=0.603-0.157 \mathrm{ROA}
$$

Keterangan:

$\mathrm{AGE}=$ usia perusahaan

$\mathrm{ROA}=$ return on assets 
Hasil analisis data variabel usia perusahaan terhadap ROE dapat diketahui pada tabel berikut ini:

Tabel 3.

R Square Usia Perusahaan terhadap ROE

\begin{tabular}{ccccc}
\hline Model & $\mathrm{R}$ & $\mathrm{R}$ Square & $\begin{array}{c}\text { Adjusted R } \\
\text { Square }\end{array}$ & $\begin{array}{c}\text { Std. Error of } \\
\text { the Estimate }\end{array}$ \\
\hline 1 & $.124^{\mathrm{a}}$ & .015 & -.017 & 17.32894 \\
\hline a. Predictors: (Constant), AGE & &
\end{tabular}

Tabel 3 diatas menunjukkan angka $\mathrm{R}$ square sebesar 0,015 yang berarti bahwa variabel usia perusahaan mempengaruhi ROE sebesar 1,5\% dan sisanya sebesar 98,5\% dipengaruhi oleh variabel lain selain usia perusahaan.

Tabel 4.

Pengaruh Usia Perusahaan terhadap ROE

\begin{tabular}{ccccccc}
\hline \multirow{2}{*}{ Model } & \multicolumn{2}{c}{ Unstandardized Coefficients } & $\begin{array}{c}\text { Standardized } \\
\text { Coefficients }\end{array}$ & \multirow{2}{*}{$\mathrm{t}$} & \multirow{2}{*}{ Sig. } \\
\cline { 3 - 5 } & \multicolumn{2}{c}{$\mathrm{B}$} & Std. Error & Beta & & \\
\hline \multirow{2}{*}{1} & (Constant) & 1.876 & 9.214 & & .204 & .840 \\
& AGE & -.918 & 1.337 & -.124 & -.687 & .497 \\
\hline
\end{tabular}

a. Dependent Variable: ROE

Tabel 4 diatas menunjukkan angka sig sebesar 0,497 yang berarti bahwa variabel usia perusahaan tidak berpengaruh signifikan terhadap ROE. Persamaan regresi untuk pengaruh terhadap ROE adalah sebagai berikut:

$$
\mathrm{AGE}=1.876-0.918 \mathrm{ROE}
$$

Keterangan:

$\mathrm{AGE}=$ usia perusahaan

ROA = return on equity

Hasil analisis regresi menunjukkan bahwa usia perusahaan tidak berpengaruh terhadap ROA dan ROE. Hal ini disebabkan karena pangsa pasar bank syariah baru mencapai 6,01\% pada tahun 2019 (Sitanggang, 2019). Hasil penelitian ini senada dengan penelitian yang dilaksanakan oleh Younis \& Sundarakani (2020) yang menunjukkan hasil bahwa tidak ada pengaruh usia perusahaan dengan kinerja. Berdasarkan hasil penelitian ini, maka manajemen Bank Victoria Syariah harus berusaha meningkatkan pangsa pasar untuk menambah kinerja keuangan misalnya dengan menggencarkan promosi dan kerjasama korporat. 


\section{KESIMPULAN DAN SARAN}

Hasil analisis regresi menunjukkan bahwa usia perusahaan tidak berpengaruh terhadap ROA dan ROE di Bank Victoria Syariah. Hasil penelitian ini senada dengan Younis \& Sundarakani (2020) yang menyimpulkan bahwa tidak ada pengaruh usia perusahaan terhadap kinerja keuangan. Saran untuk penelitian selanjutnya adalah meneliti tentang faktor lain yang mempengaruhi kinerja, misalnya kepemilikan institusional (Artha et al., 2021).

\section{DAFTAR PUSTAKA}

Artha, B., Bahri, B., Sari, N. P., Sari, U. T., \& Manurung, U. R. (2021). The Institutional Ownership and Firm Performance: Evidence from The Capital Bank. Journal of Business and Management Review, 2(7), 445-456.

Bajpai, N. (2018). Business Research Methods. Pearson India.

Baum, J. A. C., \& Ingram, P. (1998). Survival-enhancing learning in the Manhattan Hotel Industry, 1898-1980. Management Science, 44(7), 996-1016.

Cheng, Z., Fleming, G., \& Liu, Z. F. (2017). Financial constraints and investment thirst in Chinese reverse merger companies. Accounting and Finance, 57(5), 1315-1347.

Chincarini, L. B., Kim, D., \& Moneta, F. (2020). Beta and firm age. Journal of Empirical Finance, 58, 50-74.

Coad, A., Segarra, A., \& Teruel, M. (2016). Innovation and firm growth: Does firm age play a role? Research Policy, 45(2), 387-400.

Desai, V. M. (2008). Constrained growth: How experience, legitimacy, and age influence risk taking in organizations. Organization Science, 19(4), 594-608.

Fan, S., \& Wang, C. (2021). Firm age, ultimate ownership, and R\&D investments. International Review of Economics \& Finance, 76, 1245-1264.

García-Quevedo, J., Pellegrino, G., \& Vivarelli, M. (2014). R\&D drivers and age: Are young firms different? Research Policy, 43(9), 1544-1556.

Gestanti, L., \& Setiawan, R. (2019). Usia CEO dan Kinerja Perusahaan. Jurnal Ilmiah Manajemen, 9(1), 1-5.

Glambosky, M., Jory, S. R., \& Ngo, T. N. (2020). The wealth effects of mergers and acquisitions by dividend payers. The Quarterly Review of Economics and Finance, 78, 154-165.

Gugler, K., \& Szücs, F. (2016). Merger externalities in oligopolistic markets. International Journal of Industrial Organization, 47, 230-254.

Haykir, Ö., \& Çelik, M. S. (2018). The Effect of Age on Firm's Performance: Evidence from Family-Owned Companies. Ömer Halisdemir Üniversitesi İktisadi ve İdari Bilimler Fakültesi Dergisi, 11(2), 129-137.

Hoffman, J. P. (2021). Linear Regression Model Applications in R. CRC Press.

Kieschnick, R., \& Moussawi, R. (2018). Firm age, corporate governance, and capital structure choices. Journal of Corporate Finance, 48, 597-614.

Petruzzelli, A. M., Ardito, L., \& Savino, T. (2018). Maturity of knowledge inputs and innovation value: The moderating effect of firm age and size. Journal of Business Research, 86, 190-201.

Olarewaju, O. M., \& Msomi, T. S. (2021). Intellectual capital and financial performance of South African development community's general insurance companies. Heliyon, 7(4), e06712. 
Ouimet, P., \& Zarutskie, R. (2014). Who works for startups? The relation between firm age, employee age, and growth. Journal of Financial Economics, 112(3), 386-407.

Sitanggang, Laurensius Marshall Sautlan (2019). Alhamdulillah, usai 28 tahun akhirnya pangsa pasar perbankan syariah tembus 6\%. Tersedia di https://keuangan.kontan.co.id/news/alhamdulillah-usai-28-tahun-akhirnya-pangsapasar-perbankan-syariah-tembus-6. Diakses pada Oktober 2021.

Vimalnath, P., Gurtoo, A., \& Mathew, M. (2018). Patent characteristics and the age-value relationship: study of OceanTomo auctioned US singleton patents for the period 20062008. $R$ and D Management, 48(3), 271-289.

Woetzel, J., Seong, J., Leung, N., Ngai, J., Manyika, J., Madgavkar, A., Lund, S., \& Mironenko, A. (2019). China and the World. McKinsey Global Institutes, July, 447476.

Younis, H., \& Sundarakani, B. (2020). The impact of firm size, firm age and environmental management certification on the relationship between green supply chain practices and corporate performance. Benchmarking, 27(1), 319-346. 